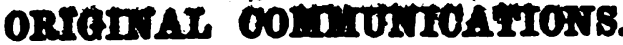

\section{REMEDIAL EFFECTS OF MINERAL WATERS, HOME AND FOREIGN.}

By R: HUTChinson POWfLL, M.D.Lond., late Physician to the Blenheim Dispensary, Vice-President of the

Harveian Society, etc.

BECTION I. INTRODUCTORT REXARKS OY MIMERAL WATERB. TrEas are few subjects in the extensive field of practical medicine to which careful research has not been directed. and jet, how often is one apt to overlook comperatively trite information, either from early impressions leading to routine treatment, or want of well founded confidence in the agents at our command! I suspect that some such causes have been in operation, leading to the partial or total disuse of the very admirnble and highly efficient form of medicinal agents here referred to. We have many treatises, foreign and domestic, on mineral waters, setting forth their efficacy in combating disease, or, at all events, its antecedent, functional disorder; and yet, how few in the profession use them! Do they not rather prescribe them 28 dernier ressort-as a sort of therapeutic scape-goat for the indifferent success of more potent means, and by way of borrowing an idea from the homoopath's reveries? No man can practise his profession successfully at the present day without a confident and decided bearing towards his patients, who speedily perceive any want of this indispensable qualification; nor of course can any considerate practitioner lay down a system involving expense, discomfort, etc., without well founded reliance upon it. In the following remarks it will be my object, necessarily in a very general way, to elucidate the circumstances which should determine the selection of this class of remedies; indicating those often indistinctly marked and intractable states of the spstem in which they are peculiarly applicable; and incidentally pointing out and substantiating the claims of mineral waters to our confident attention. I proceed to make a few general observations upon the latter head.

There can be little doubt that the healing art would derive benefit from a revision of the mode in which the several constituents of our materia medica act. How many operate merely as mechanical agents, by protecting irritated surfaces; or by means of endosmosis or exosmosis, etc.? Of the majority which take an active part in the chemical transformations incessantly going on in the system, what is the precise office filled by each? What number act 80 inscrutably as to defy the most acute observation? These, though at present not few, will continually decrease, from the more enlightened method of investigation obtaining of late years. Such are some of those complicated questions involved in any inquiry of this nature; and it is obvious that rational views, as well as successful practice, will attend our efforts to combat morbid operations, in proportion as we unravel and define, as closely as inperfect data will permit, the kind and amount of extraneous influence brought to bear upon their removal.

One of the most obvious distinctions between saline bodies in common use, and those contained in mineral waters, arises from the minute portion present in the latter instance; the saline matter attaining a degree of solubility not shared by any other remedies. In the solutions extemporaneously made in pharmacy, one is apt to think, that because the menstruum becomes transparent, the highest degree of union has ensued between it and the contained substance. But there is reason to conclude, that combinations of a more complex and permanent character are formed, and that more perfect diffusion takes place, where favouring circumstances hold as to the quantity, the temperature, the gaseous constituents of the solvent, etc. Professor Graham's ingenious experiments as to the varying diffusibility of difforent saline solutions when suspended, and partially isolated in water, anggestive of diverse affinity, woll illuotrate this point. A mineral wator when ingouted, it them slmost

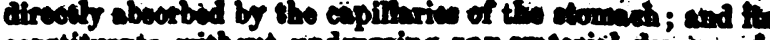

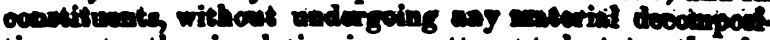
tion, enter the circulation in in attenusted ata; troms gaining access into the penctralia of the vital operntions and reciprocating with the contained luid in all its subere queat changes. This is an obrious source of the potent clisects of mineral waters. It is not improbable that afinitien are brought to bear amongat two or more salts thus 10 frrourably circumstanced as regands combining tondenaien, which originate compound radical bodies analogous to the regetable alkaloids, or to the protein compounds of the animal ringdom, not determinable by analysis, but whose presence is recognised by their effects in modifying diseased vital procesese, and converting them to healthy action.

These considerations will have more weight, if the intolerant state of the digestive nucous membrane be borne in mind in very many chronic maladies, in which ordinary medical doses, far from remoring disease, only aggravate suffering. Nature plainly denotes, in this class of remedies, the very gradual process by which changes are to be brought about in the human economy. A minute dose of mineral bodies is taken for a lengthened period, and such effect as pertains to each is almost imperceptibly induced : thus approximating to and harmonising with the ordinary assimilation of the materials which make up the healthy fabric. The presence of saline substances, as necessary constituents of the fluids and solids of the body in health, would further indicate mineral waters to be often alimentary rather than medicinal agents. Again, it is found that the presence of saline bodies in the blood, urine, or other fluid containing blood-disks, prevents that rupture of their capsules which would otherwise ensue from undue endosmosis of the aqueous constituent.

This class of remedies, moreover, is to be distinguished from many bodies of vegetable, animal, or mineral origin, by requiring no vital process for reception into the vascular system; this is an important feature, as the latter medicinal agents probably undergo many transformations, and considerable change of properties by the digestive process, and may require absorption by the agency of cells, prior to reaching the same destination. Further, soluble salts may be intercepted by the membranous walls of the capillaries; not having entered into that perfect solution and union with water, attained in the case of mineral waters. Again. a very dilute solution may gain admission through epithelial investments, which would resist more concentrated saline liquids either from the purely constringent effects, or from the morbid sensibility present.

The external applicution of mineral waters, in the form of baths, opens out an efficient method of introducing remedies into the economy not afforded by ordinary means.

Such are a few of the causes which might be assigned in explanation of the poculiar claims of mineral waters to the favourable consideration of the prescriber ; being sufficiently numerous and weighty to justify our confidence, and to satisfactorily account for any favourable result. Of course, numerous collateral influences contribute to this end; but enough remains to vindicate their claim to be considered highly useful and potent agents in the removal of incipient disease. Hence, without adverting further to the point at issue, I shall pass on to make a few remarks upon the principal mineral waters of this country and the continent; dividing them according to their most active constitucnts, and the peculiar effects of each. Thus will require to be passed in review, the circumstances determining their use in the treatment of abnormal vital conditions.

I have here selected that classification which more immediately bears upon the curative action of mineral waters; as, although it is not free from objections, a readier application to practice may be attained in this way than when the springs are classed chiefly under the head of operative or chemical constituents. Moreover, as above suggested, wo are perhaps not in a position to specify with accuracy the precise and intimate constitution of each spring, as existing naturally.

Mineral waters mas be grouped under four primary divi- 


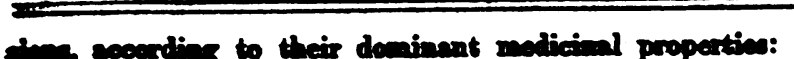

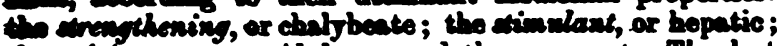
the refrigerewe, or scidulous; and the emanant. The lact sroup comprises many and rery important springs; haring all intormediato proparties, from almost insensibly affecting the secreting and other organs, to exerting a potent action on the excretions, one passing imperceptibly. into another of the same division. The diuretic or resolvent waters of this division, from their alkaline or earthy constituents, exert a very marked influence on the economy, especially in urinary disorders, gouty and rhoumatic diseases, dropsical and other affections more particularly depending for their origin on morbid products in the circulation, and might well merit a distinct heading. Of course an absolute separation could not be looked for in the peculiar effects of each spring; but, analogous to the usual constituents of a prescription, it will be found for the most part to consist of a base or dominant principle, an adjuvant, a corrigent, and vehicle or medium through which to act upon the system, two or more being combined in each. Some springs approach in minor qualities to others of a different class; thus chalybeates usually coustringe the bowels equally with calcareous salines. Springs possessing scanty chemifal con: stituents, as Malvern, evince remarkable effects, at tributable sometimes to the thermal condition, or to the immediate influence of the ingestion of a large amount of pure water.

This influence has been vaunted into the so-called system of hydropathy - at least so far as the internal application of water constitutes this pathy. It is a freely admitted and generally received truth, that the reception of water into the system, in virtue of its special action, does operate on the digestive organs, more particularly on the liver and kidneys. The researches of Bernard go to show, that any fluid taken in amount above what is immediately demanded by the economy is quickly removed through a retrograde action of the portal vein, whereby the surplus is directly ejected from the system through the kidneys, by special hepatico-renal vessels. Water forms an essential constituent of the frame, making four-fifths of its total weight. It pervades all structures, conveying nourishment to all parts of the frame, diluting more stimulating fluids, depositing, separating, and carrying away effete matter. The loss continually occurring from secretion is repaired. Pure water, moreover, favourably influences the vital condition of the digestive mucous membrane; its tone being maintained under varying functional vicissitudes.

Many alimentary substances are dissolved and become absorbed for the purposes of the economy, which otherwise would pass through the digestive tube unacted upon. It is worth observing that the atmospheric air contained in water differs in the relative proportion of its constituent gases, the proportion of oxygen being greater; hence may be derived some of those important offices subserved by water in the human economy. When hydro-sulphuric acid gas, or protocarbonate of iron, or organic matter is present, the oxygen is of necessity abstracted by the play of chemical affinities set up.

Such are some of the properties of this indispensable fluid. It is an agency which, discreetly wielded, effects much good; but, like any other physical or moral agent, when the just gradation is overstepped, or where it is prescribed in unsuitable conditions of the system, water may become an instrument of evil in the hands of the ignorant or unscrupulous.

Some springs of the evacuant class are so modified by extreme dilution, that the debility otherwise caused by the ingredients in a concentrated state is aroided. Others, though evacuant, impart tone to the intestines from some secondary constituent, or from their temperature, and thus oppose the depressing effects of cracuants, their protracted use being permissible-a practice so peculiarly beneficial in the remedial influence of mineral waters.

The English springs for the most part differ from continental in the comparatively isolated condition and small amount of their medicinal ingredients; so that their application is more simplified, though often less poteat, than that of foredga springa. $\Lambda$ choice mas be made acconding to the indientions in weh case.

It may here be remarked that the observations made under each head, will refer (unless otherwise specitied) to all the springs of the same division; one being given as typical of the rest. A minute notice of each would be incompatible with the limits of this sketch. By stating the constituents of each spring of repute under the generic heading, an indication may be readily arrived at as to its medicinal properties and applicability.

\section{SECTION II. TONIC BPRINGS.}

The chalybeate spring of Tunbridge Wells is remarkable from its lengthened repute, and acknowledged efficacy. It is comparatively simple in constitution; the principal constituent being protucarbonate of iron. It will therefore readily fall in with our proposed arrangement.

There are contained in a wine pint about-

\begin{tabular}{|c|c|c|c|c|c|}
\hline Protoside of iron & & - & - & & 0.26 \\
\hline ( calciuu & - & & & & 0.18 \\
\hline Chlorides of magnesiun & & - & - & - & 0.04 \\
\hline Sulphate of soda & $\dot{-}$ & $\because$ & 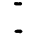 & : & 0.18 \\
\hline Carbonate of lime & - & - & - & - & 0.04 \\
\hline Oxide of manganese & - & & - & - & 0.06 \\
\hline
\end{tabular}

\section{And of-}

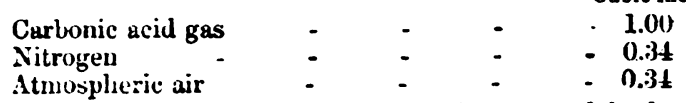

This water is clear, has an inky smell and taste, and is decomposed on applying heat, or exposure to the air.

In this spring, from its containing but little saline matter; an intimate uuion with the iron is effected, its good effects being thereby enhanced. The salts of iron have a wide range of action on the system, and exert a beneficial or reverse influence, according to the nature or stage of the diseased operations to combat which they are exhibited. $\Lambda$ part from the undoubted play of chemical affinicies in which iron takes a share in the constitution of the blood, bile, and other animal fluids, there are good grounds for considering its operation to consist for the most part in an impulse being giren to the organism, whereby its inherent assimilative forces aro stimulatad to increased and healthy action. An improvement takes place throughout the entire economy; the nervous system, heart, lungs, abdominal organs, etc., rererting to a normal type of structure, and healthy function, by the process of repair and elimination of effete matter being duly accomplished.

The chalybeate mineral waters are indicated in persons of bulky frame, but with relaxed and weakly muscular development, attended with torpid circulation, and an inactive turn of mind. It is especially efficacious when bodily powers fall below par, either as an immediate consequence of insufficient susteuance, or alsstraction of blood ; or in a more remote way supervening on undue excitement or sympathetic derangement of function. The capillary vessels become relaxed, the nervous system unstrung, and all the related organs and tissues deteriorated. The impoverished condition of the blood is evinced in the features, and in the embarrassed performance of all the functions-indicative of loss of power, and eventually of deeply rooted disorder; the secretions and excretions being defective or vitiated. It nay be remarked that, although in general tonic remedies are unsuitable in organic affections, yet in those attended with a severe drain of blood (carcinomatous disease), the exhibition of iron seems to retard the break up of the system, by affording material for a prompt formation of fresh blood. Among the obscure states of system in which mineral waters of this division may be used with advantage, that which simulates inflammatory excitement is deserving of special notice, as presenting some of its symptoms. This condition is distinguished by the anæmic and worn aspect, by the excitable and feeble pulse, and other indications of 
the pationt's atony; dicorder of the benin, heart, reopin etory, digeative, and nerrous systemes, reopectively partike of the disguise. This state may be associated with vascular repletion; the contained fluid being howerer imporerished, but giving a puffy and distended, and oren florid, appearance to the features. Uterine disonder-whether as regands retention, irregularity, or excess, or vitiation of catamenial discharge, irritability, or other defect of function, - assumes a conspicuous place in those complaints favourably influenced by chalybeate water, and forms the salient point in a numerous class of affections to which females are particularly obnoxious. Uterine disorders, the results of malnutrition and constitutional debiitity, are those for which chalybeates have a special curative affinity.

An indiscriminate recourse to pure tonic springs is highly reprehensible in unsuitable cases of the latter class of complaints. The habit of body, the kind and stage of disordered functions, the state of the alimentary canal, as regards freedom from irritation, a not too great erethism and general nervous excitability, are among the circumstances which should guide the practitioner in their application. Uterine irritability from spinal irritation may not prohibit their use, provided the disorder partake of the nervous charaster-periodicity with neuralgic pain, but with little or no appreciable anatomical change, and attended with undue mobility of the nervous system, and with other constitutional signs of impoverished blood and depressed nervous energy. Moreover, a course of chalybeate mineral waters may be advantageously associated in treatment with local depletion, and with other means, if indicated. Not unfrequently an accurate estimate of all the attendant circumstances, as regards the general operation in contradistinction to the local effect, proclivity to hæmorrhagic complaints, period of life, etc., must be carefully made, before a selection of these mineral waters is decided on.*

Those cases of uterine complaint in which capillary excitement (except very slight in degree), at all approaches congestive or inflammatory irritation, or organic disease, would be only aggravated by ferruginous waters. It is to be observed, however, that the morbid sensibility, occasionally ensuing on their use, is often but a sign of local and curative reaction, and may not always require their withdrawal, provided other circumstances indicate their continued use; the intervals of catamenial indisposition being, however, the only periods in which the remedy is applicable. The system, though not admitting of tonic waters, may, by the preparatory use of, or intermixture with, others of a different class, + be rendered tolerant and amenable to chalybeates. $A$ careful regimen and mode of life will of course powerfully promote their action, and ward off sources of failure and functional disturbauce.

Among those disorders of the digestive organs benefited by the chalybeate waters, that form of indigestion may be particularly mentioned which is connected with feeble circulation, and characterised by a feeling of cold and weight over the stomach, with oppression, loss of appetite, nausea, flatulence, eructations voided in large quantity, and confined bowels, pale urine, efc.; the tongue is white and clammy, indented at the edges; headache is complained of,

- The writer takes this opportunity of most emphatically protesting against rery unwarrantuble use maile by a correspondent of the Homeopathic Times (Oct. 25th, 1832), of an unguarded expression occurring in a little work published on Tunbridge Wells. Because Dr. Granville's inconsistenoy is exposed in slighting the Tunbringe chalybeale, Whlst he deprecalos the ineauwous use of the Bath walers, though containing some ron-ergo, this sapient disciple of Hahnemanin concludes that the efficacy of infinllesinal doses is ine reminded chat a miunte dose, which is recngnisable by chemical reagents, differs toto caro from one entirely inaprecing rathonal mind psewo-medical phllosophers fonnd their vauned "inestion yme that they wilully ignore the dispassionace investyalon it has long ince received from the profession. Granted, that an occasional coincidence ans seem to favour their dogma, when dissevered from its legitimate oonmext acnersil principle, th the overthrow of a mass of opposing facts?

general principle, tn the overihrow of a mass of opposing facts ? 4 The artitcial mineral waters of Brightou, which are prepared with graat are, and close epproximation to the respective natural sptings, chon happs adaptition to the contict

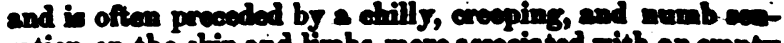
ation on the shin and himbe, moro sevecielad with an compts atomach than otherwise, and is induced by fanting or orer exertion. These symptoms are recurrent, often without apparent cause, or by impressions affecting the emotions, changes of weather, etc. Disturbance of the nerrous function induces giddiness, noises in the ear, deafness, dimness of sight. I have mentioned these symptoms in some detail, as it is of great importance that this form be not confounded with other varieties attended with a congested state of the digestive mucous membrane, which may be better combated by mineral waters of an opposite character. A course of ferruginous mineral water may, however, be tolerated, and had recourse to earlier than is permissiblo with ordinary tonics; for the water, by its temperature and amount, tends to allay vascular erethism.

The chalybeate waters will be usefully applied in other abdominal derangements-debilitated conditions of the digestive mucous membrane, attended with diarrhoea, tendency to verminous invasion, and in passive hrmorrhage; in tubercular dyscrasia, arising in young persons, and accompanied in children with tumid belly and unhealthy alvine discharges flaccid muscles, enlarged tonsils, with early liability to chilblains; in serofulous disease, manifesting itself in the joints, glandular organs, etc.; in certain chronic enlargements of the liver, spleen, and related dropsical disease; in atonic states of the kidneys and bladder; in certain cardiac affections (thinned and dilated walls, with fatty or other metamorphoses, angina, etc.); in various nervous diseases, general and local; in cutaneous eruptions, inordinate sweating, etc., attended with sabulous disorder, and faulty digestion, occurring in debilitated persons; in chronic arthritic affections, accompanied with general depression of strength and health. This list might be further extended; but enough, if not too much, has been cited to show that it is not the mere localisation of disordered action (which typifies the cases in which ferruginous springs are specially efficacious), but that constitutional debility upon which the disorder is grafted. The choice of any one spring in this division wilk depend upon minute circumstances of detail pertaining to each case, which could not be specified in this brief sketch, but which are not the less important as regards the result.

Chalybeate waters are contraindicated in persons of the sanguine temperament with rigid fibre, and when there exists a predisposition to inflammatory disease or active hæinorrhage; also in acute diseases generally, attended with febrile irritation or structural alteration in any organ; in cases where an irritable condition of the heart or bloodvessels is present; wherein the circulating fluid is impure, or superabundant in plastic material or quantity-plethora; where congestive determination to the head or chest exists. These waters must never be used where an inflammatory condition of the alimentary canal is present; of which the tongue having a red, livid, or glazed appearance, affords a good, though not an invariable indication.

In concluding the above catalogue of diseased states of the system beneficially influenced by tonic springs, a list is appended of all springs belonging to the tonic division; the last mentioned approximating to evacuant springs.

Proportions in a wine pint (sixteen fluid ounces) of water, about-

Harrogato Brucknau, Pouhon of Pyrmont, Eger, Jeviltwell. 510 Fah. 8pa, 50\% F. $56 \circ \mathrm{Fah}$. $540 \mathrm{Fah}$ \begin{tabular}{llll} 
grs. & grs. & grs. & grs. \\
\hline
\end{tabular}

$\begin{array}{llllllllll}\text { Protoxide of iron } 0.25 & \ldots & 0.25 & \ldots & 0.37 & \ldots & 0.40 & \ldots & 0.24\end{array}$ Alkaline \& earthy
salts -

$$
\begin{aligned}
& \text { Total }-\overline{1.05} \ldots \overline{2.36} \ldots \overline{4.08} \ldots \overline{19.27} \ldots \overline{39.41} \\
& \text { Cub. in. Cub. in. Cub.in. Cub.in. Cub.in }
\end{aligned}
$$

Carbonic acid gas $0.50 \ldots 36.50 \ldots 38 . \quad \ldots 44 . \quad \ldots 43$.

The Schwalbach watet is a saline chalybeate, containing protocarbonate of iron, carbonates of magnesia, lime, and soda, with free carbonic acid gas.

-The Homberg and Kreuznach waters connect the chalyyineate with the resolvent class, and they are very potent 


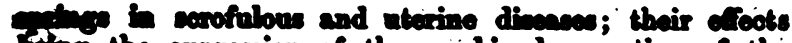
CAln the expresion of the combined operation of the anvel constituentio on the syetem. According to Gorman inthorities, eren fibroid tumours of the uterus and orivies, and certain enlarged states of thece organs, are susceptible af remoral and cure by the use of the Kreusnach wateran ascertion not improbable from the capillary permeability of these structures afionding the requisite channel for the removal of morbid products, and formation of normal tissue. Moreover, these powerfully resolvent and stimulant waters admit of supplemental application, where the chalybeates are inadmissible or powerless.

A pint of the Homburg water contains about $77 \frac{1}{3} \mathrm{grs}$. of chloride of sodium, nearly 2 grs. of chloride of potassium, 15 grs. of chloride of calcium, 6 grs. of carbonate of magnesia, 41 grs. of carbonate of lime, one-tifth of a grain of carbonate of iron, with a trace of bromide of sodium -in all $107 \frac{\mathrm{s}}{\mathrm{grs}}$, and $37 \frac{1}{8}$ cubic inches of carbonic and gas. $A$ pint of the Kreuznach water contains $80 \mathrm{grs}$. of chloride of sodium, $1 \mathrm{gr}$. of chloride of potassium, $13 \mathrm{tgrs}$. of chloride of calcium, onefourth of a gr. of chloride of magpesium, bromide of sodium nearly one-third of a grain, with a trace of iodide of sodium, If gr. of carbonate of magnesia, nearly 1 grain of other earthy carbonates, and one-fifth of a gr. of carbonate of irith -in all 901 grains, and 31 cubic inches of carbonic acid gas. A pint of the Saratoga Congress spring (analogous to these) contains 24 grs. of chloride of sodium, 2 grs. of chloride of potassium, 8 grs. of carbonate of lime, $5 \frac{1}{\mathrm{~g}}$ grs. of carbonate of magnesia, a trace of carbonate of iron, one-fifth of a grain of bromide of sodium, a trace of iodide of sodium-in all 44 grains, and 32 cubic inches of carbonic acid gas.*

It will be observed, that the continental chiefly differ from the English chalybeate springs, in containing a larger a mount of carbonic acid gas; which gires to them a more agreeable flarour, greater digestibility, and otherwise affects the system farourably. We shall have to notice this ingredient under the head of refrigerant waters; merely remarking that they are contraindicated when much flatulence exists. Tunbridge Wells spring acts as a local astringent on relaxed states of the mucous membrane of the bowels more than others, as not being so quickly absorbed. The Tunbridge Spa is not used externally, nor are springs of this class 80 much had recourse to on the continent, in the form of baths, as those of other divisions; there are, however, many cases in which iron cannot 80 safely enter the circulation, as through the cutaneous surface.

BECTION III. BTIXULANT gPRINGS.

In briefly considering the stimulant or hepatic springs, I shall select for illustration the old sulphur spring of Iower Harrogate; in which locality, however, there are in use two more sulphuretted saline, one pure saline, three chalybeate, one saline chalybeate, and one saline sulphuric chal ybeate.

There are contained in a pint of the Old Sulphur Well, about-

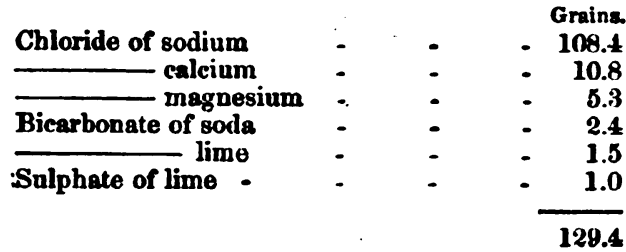

$-\quad-1.7$

Carbonic acid gas - $\quad$ - $\quad$ - $\quad$ - 1.2

Nitrogen and carburetted hydrogen gases - $\quad .7$

3.6

The second or Montpellier sulphur spring contains a little less chloride of sodium, but somewhat more chloride of palcium and maguesium, and is more highly charged with the

- All the oprings meationed in this paper are cold, when the termpachipe hopatie gas. The remaining sulphur epring, the Btarbech, does not contain more than ono-erenth of the amme alive constituents as the two firet, and one-thind of the sulphurs etted gas; and afionds a mild spring of this character. The other springs of Harrogate will be referred to in the lat division. The Aix-la-Chapelle mineral water diffors chiefly in being a hot spring (113 Fahr.), in a pint contains 13.3 cubic inches of hydro-sulphuric gas, and about 25 grains of aline ingredients similar to those of Harrogate. Tho Berdges spring, in the Pyrenees, is also o thermal sulphurous spring, but weak in sulphuretted hydrogen gas and salts. The mineral waters of Bonnes, Cauterets, come under the head of stimulant or hepatic springs, and hare similar constituents, varying in power according to the smount of ingredients present. The sulphurous spring at Moffat, in Scotland, is cold, and contains a proportionably small quantity of hydro-sulphuric gas and muriatic salts.

The waters of this division have the well known odour of sulphuretted hydrogen, and a salt taste. Disagreeable eructations ensue after they are swallowed. The water $800 \mathrm{n}$ loses transparency on exposure to the air, but may be preserved without much alteration if securely bottled.

The hydro-sulphuric acid gas suspended in these waters seems to undergo absorption through the prima via, and is probably decomposed on entering the circulation. The sulphur constituent, when acidified by oxygen, lessens the crassamentum of the blood, rendering it poorer in red globules, and more fluid. Sulphuretted hydrogen gas acts especiall' on the cutaneous and uterine tissues, and exerts a very wide though almost imperceptible action on the functions of the economy at large. Sulphur forms a necessary element of some of the proximate constituents of the solids, and no doubt takes an essential part in the chemical transformations constantly going on in the circulating fluid.

The other constituents of these waters harmonise in action with the hepatic gas; especially influencing the mucous membrane of the prime vire and urinary canals; and seeming to exert a counteractive and deobstruent influence on the solid digestive organs, when obstructed or tending to in. cipient decay; these, however, will be more appropriately referred to under the next division.

Amongst the special diseases receiving benefit from this class of springs, may be enumerated some of those mentioned under the first division, -or chlorosis, in which a chalybeate spring will often complete the cure; or amenorrhow with nuch languor and depression, and where chalybeates have been unavailingly used. A nice discrimination is often required in the selection of an appropriate spring in these cases ; some requiring and even bearing the evacuant action occasionally consequent to the use of the stronger sulphurous waters; others, again, needing a carbonated saline, so as to soothe highly sensitive subjects with irritable digestive and urinary organs, before entering upon those more exciting mineral waters.

Cases of chronic gout and rheumatism in elderly persons of feeble powers, will often derive great benefit from sulphurous springs, if taken with caution, and in conjunction with other suitable means. Many dyspeptic complaints yield to them, which resist other treatment; more especially the atonic forms before indicated, when attended with cardialgis.

The sulphurous waters are occasionally used with much adrantage in biliary disorders, with torpid liver, and alvine inaction ; in hypochondriacal states of the system; in verminous invasion of the alimentary canal, in which intructable disorder the sulphurous water often expels the parasitic growths, simultaneously strengthens the mucous membrane, and thus prevents their regeneration.

The specific action of sulphur on the cutaneous tiscove, renders these waters remarkably efficacious in numerous eruptive diseases, otherwise very intractable. Amongat these may be particularly mentioned the squamous orderlepra, psoriasis; herpetic eruptions, scabies, etc.

Theos stimulant waters have been found useful in that state of dyscrasic preceding tuberculous discases, in which they ceem to exert a powerful depurating and altorative 


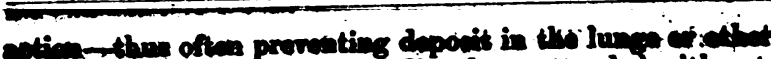

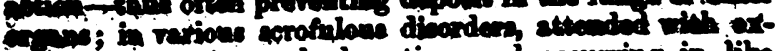
1.il mppuretion and uloeration, and occurrins in lits ritios of the aystem, and in scorbutic and analogoan anoo lime

These eprings are conlra-indiouted in much the same conitivitional conditions and disenses as the chalybeate chasePethoric, inflammatory, or fobrile states of the system. there often exists, however, a neutral or doubtful clace, a periods of transition from an acute to a chronic character, in some intractable disorders, and arising in persons of weekly powers, wherein these waters may be sufely used, clthough at first view seemingly inappropriate. It is in these cases especially that the practitioner's skill is erinced; and no doubt, like other remedies, this class occasionally comes into diarepute when used in certain disorders, or tages of a complaint requiring auxiliary or different means.

SECTION IV. REPRIGERANT BPRINGS.

We pass on to springs of the third or refrigerant division. These waters have an agretably sharp taste, and chiefly owe their properties to the large quantity of free carbenic acid gas present, together with a notable amount of alkaline and earthy muriates, and have a relation with the chalybeate clase from the ingredients common to both mineral waters. The only spring coming under this head in Fngland is that of Ilkeston, near Nottingham, possessing very little saline or a arating constituents. The Seltzer spring of Nassau exhibits the predominant gaseous property in perfection, and is almost as much domesticated as the artificial sodaic waters in ordinary use. It consists, in a pint, of -

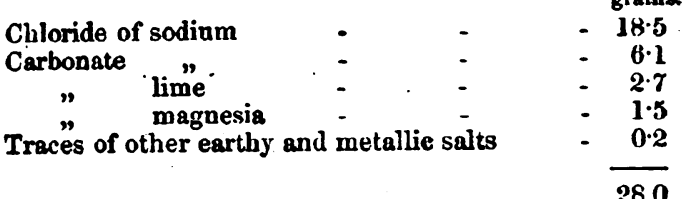

Carbonic acid gas $34 \cdot 3$

Temperature $58^{\circ} \mathrm{Fahr}$

The Geilnau spring has very similar constituents, containing in a pint about mine grains of alkaline and earthy carbonates, with minute portions of sulphates and phosphates; and a small fraction of carbonate of iron. Fachingen contains about twenty-four grains of alkaline carbonates, and both being highly charged with carbonic acid gas. The springs of Ems, Vichy, and others, are also highly impregnated with carbonic acid gas; but it cannot be so moll considered as the dominant ingredient, from the large amount of alkaline and earthy salts present giving them special properties which we shall notice under the last head.

A pint of Fachingen (refrigerant) mineral water contains $16 \frac{1}{2}$ grs. of carbonate of soda, $2 \frac{1}{2}$ grs. of carbonate of lime, $17 \mathrm{gr}$. of carbonate of magnesia, $4 \frac{1}{\mathrm{~s}} \mathrm{grs}$. of chloride of codium, with 38 cubic inches of carbonic acid gas. A pint of Adelheidsquelle, contains 7 grains carbonate of sods, 37 grs: of chloride of sodium, with 3 cubic inches carbonic acid gas, as the principal constituents.

Water charged with carbonic acid gas, when receired into the stomach, acts as a sedative upon the mucous membrane, llays thirst, and exerts a slightly inebriating sensation through the organic nerres, which quickly passes off. It eppears to promote the digestive process, in those not suffering from fatulence, by increasing the gastro-intestinal and hepatic secretions; and, by its action on the kidneys, the urinary secretion is also sugmented and modified. It exerts a sodatife effect in irritable states of the alimentary anal and, in fine, cooperates with the other constituents of a spring by promoting their perfect colution and suspension.

Waters of this division are advantageously prescribed in irritable canditions of the gatro-inteatinal mucous mombane, thet of the biliary and penereatic glands being also inflionted the leadion to. billary derangement and anti-

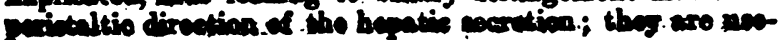

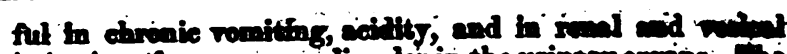

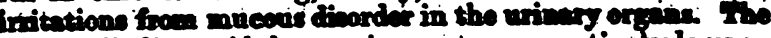
hight ell-aline scidulous springs sct more particalarly open the kidners, and are indicated in that dopraved stivite of tho blood and solids generally sccompanying the lithie acid divthexis in rhoumatic and gouty complainte. The systom, in this te, often manifests a febrile though depressed condition attended with loes of appetite and thirst; the circebation being easily excited, and the nerrous system muck deranged; the secretions and excretions also being torpid and ritiated. These waters exert a marked remedial effect in these cases, when used with discretion, and not taken in too large quantity, or for a lengthened period; otherwise, the disordered condition of the system may be rather aggravated than beneficially influenced.

\section{GECTION V. EYACUAXT BPRINGB.}

The last division now remains for brief consideration, riz., the evacuant springs. These springs comprise by far the most important of all remedial agents in this department of the materia medica: the contained alkaline and earthy salts respectively effect an excremental deportation and reconstruction of the entire system, alike of fluids and solids; and in the earlier stages of organic disease they not seldom restore the liver, spleen, kidneys, uterus, and ovaries to normal structural standard. As they are all, however, more or less stimulant, especially the thermal waters, they are not suitable in those states of system or diseases in which vascular excitement exists (in hectic exacerbations, internal and advanced consolidations or suppurations, or in those predisposed to inflammatory or apoplectic seizures). It is rather in the chronic stages of disorder that these, like all other mineral waters, come into play so happily in the treatment. The asline sulphates, muriates, and carbonates respectively form the type of this class; and the better to form a coup d'ail view of the principal springs a concise tabular statement is here given. [See next page.]

It is worth remarking, that the alkaline salts of mineral waters have a special relation with those contained in the blood, wherein soda takes an important share in the several transformations going on: hence may result much of the benefit accruing in those morbid conditions typified by diabetic, lithic acid, and other analogous disorders. Dr. Golding Bird's judicious remarks on the peculiar operation of small and frequent doses of alkaline diuretics at once indicate their mode of effecting important though gradual changes in the system. These carbonated saline springs (Ems, Vichy, etc.) are adrantageously prescribed in cases where; from weakly constitution and much nervous irritability or advancing degeneration of tissues, the other springs of this division might prove too stimulant.

The saline sulphates and muriates (using this term as more familiar than that of chlorides) have a more immediately cathartic action, determining the circulation to the intestinal mucous mombrane, and, by endosmotic action, as well as local stimulation, effecting a free evacuation of serous fluid; thus removing morbid accumulations, and in a less degree imparting tone to the capillary network of the digestive tube. All the solid organs in immediate or remote connexion with the alimentary canal are unloaded, and set in free play by their resolvent operation; the portal renous system being especially acted upon. The muriatic salts have a special relation with the assimilating organs and digestive secretions; their acid and base being respectively appropriated for the gastro-intestinal, hepatic, salivary, and pancreatic secretions. Those springs in which the saline muriates predominate are more adapted to the disorders of the mucous membranes and lymphatic vessels: thus, the Ragozi of Kissingen, the Leamington Old Well, the Cheltenham, Montpellier, Scarborough, Scarborough Salt Well, etc., prove ef eetual in removing disorders connected with the digestive mucous membrane, expelling rorms, and restoring the membrane to a healthy condition; they further, by their aetion on the absorbents, dipparse local congestions, visceral enlargements, and glandthe swelling ; thow containing iron mare particulndy 


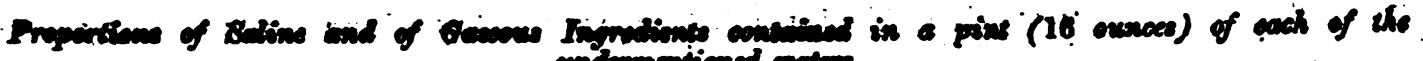

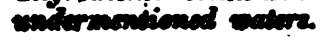

\begin{tabular}{|c|c|c|c|c|c|c|c|c|c|c|c|}
\hline - & Poulnen & solp. & 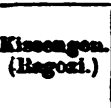 & $\begin{array}{l}1 \text { anim } \\
\text { ord }\end{array}$ & 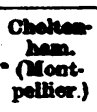 & 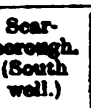 & Martenbad. & 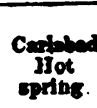 & 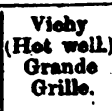 & 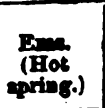 & Tromenter \\
\hline $\begin{array}{r}\text { Sulphate of sods ....... } \\
\text { magnesia.. } \\
\text { lime ....... }\end{array}$ & $\begin{array}{c}2.93 \\
123 \\
2 \cdot 5\end{array}$ & $\begin{array}{l}82 \\
23 \\
82 \\
-\end{array}$ & $\frac{97}{7}$ & $\frac{10}{=}$ & $\begin{array}{l}17 \\
14 \\
-\end{array}$ & $\begin{array}{l}\frac{812}{28} \\
28\end{array}$ & $\frac{1}{-2}$ & $\frac{1}{20}$ & $=$ & $\underline{=}$ & $\underline{=}$ \\
\hline Total sulphates .. & $218 \cdot 5$ & 105 & 7 & 40 & $3 \mathbf{r}$ & 56 & 38 & 20 & - & - & $0-21$ \\
\hline 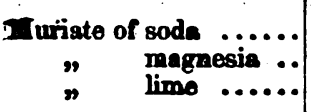 & $\overline{10}$ & 1 & $\begin{array}{r}52 \\
5 \\
-\end{array}$ & $\begin{array}{r}40 \\
3 \\
20\end{array}$ & $\frac{52}{二}$ & $\frac{3}{-}$ & $\frac{13}{-}$ & $\underline{-}$ & $\underline{4}$ & $\frac{8}{-}$ & $\begin{array}{r}15 \cdot 1 \\
1 \cdot 1 \\
2 \cdot 6\end{array}$ \\
\hline Total muriates .. & 19 & 1 & 57 & 63 & 52 & 3 & 13 & 8 & 4 & 8 & $18 \cdot 8$ \\
\hline$\underset{\rightarrow \infty}{\text { Carbonate of Soda }} \underset{\text { lime }}{\text { limesia }} \ldots$ & $\frac{-}{6}$ & $\overline{0}$ & $\overline{6}$ & $\bar{z}$ & $\begin{array}{l}1 \\
1 \\
-\end{array}$ & $\overline{0}$ & $\begin{array}{l}7 \\
\frac{1}{2}\end{array}$ & $\begin{array}{r}10 \\
2 \\
1\end{array}$ & $\begin{array}{r}28 \\
2 \\
-\end{array}$ & $\begin{array}{r}10 \\
2 \\
-\end{array}$ & $\underline{0}$ \\
\hline Total carbonates .. & 6.8 & 6 & 8 & - & $2^{8}$ & 6 & 13 & 13 & 30 & 12 & 0.6 \\
\hline 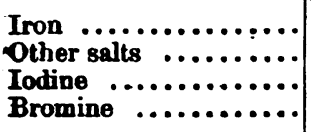 & $\overline{7}$ & $\overline{18}$ & $\begin{array}{l}0.17 \\
\frac{3}{-}\end{array}$ & $\begin{array}{l}\text { Trace. } \\
\frac{2}{=}\end{array}$ & $\stackrel{-3}{=}$ & $\begin{array}{l}0.25 \\
\underline{-}\end{array}$ & $\begin{array}{l}0.17 \\
=\end{array}$ & $\overline{3}$ & $\overline{5}$ & $\begin{array}{l}0.16 \\
=\end{array}$ & $\overline{\bar{c}}$ \\
\hline Total saline matters.. & $251 \cdot 3$ & 130 & $75 \cdot 17$ & 105 & 88 & 66.25 & $65 \cdot 17$ & 44 & 30 & $21 \cdot 16$ & 20.49 \\
\hline $\begin{array}{l}\text { Carbonic acid gas* } \ldots . . \\
\quad \text { (Cnbic inches.) }\end{array}$ & 2 & B & 20 & 2 & 11 & - & 20 & 10 & 13 & 14 & - \\
\hline
\end{tabular}

- Ascuming that a fluid pint (Bixteen ounces) of water, occupies a space of 27.7 cubic inches.

removing uterine congestion and related disorders arising from local vascular weakness, or from plethora and obstruction in the portal vessels. In dropsical swellings connected with general debility or diseased liver, etc., used in small and frequently repeated doses, the cold bitter aperient waters often prove very efficacious; as likewise in constipation, hæemorrhoids, cerebral determination, and such like affections.

The earthy and metallic salts, again, very often entering into the composition of these waters-salts of lime, magnesia, iron, etc.-counteract their depressing effects, and promote or otherwise modify their influence on the economy : hence a very wide choice is open to the practitioner. In those states of system, or of the abdominal organs, connected with chronic vascular excitement or plethora, the result of long.residence in tropical climates, intemperance, etc., the cathartic and refrigerant waters of this.dirision are indicated : hence the Püllna, Marienbad, Seidschütz, etc., are highly useful in the more active varieties of dyspeptic and hepatic disorders, attended with acidity and heartburn (especially Carlsbad and others containing carbonated salines), with headache, hypochondrinsis, hysteria, neuralgic pains, etc. These waters occasionally excite lassitude, and other febrile sensations, which, however, gradually pass off as the local disorder becomes relieved from free secretion and excretion set up. The calcareous and magnesian salts are available in spinal caries, and other articular diseases wherein these structural basic constituents are defective or lost.

There are many other constituents entering into the composition of mineral waters (Kreusnach, Woodhall in Lincolmhire, etc.), which, though in minute quantity, no doubt exert a potent operation on the body; as the salts of iodine, bromine, alumina, silica, ete, mare especially affecting the glandular system, and often wanding off the development of ecrofula, pulmonary consumption, etc. But it must be acknowledged that, after the most rigorous analyais, mineral water still produce effects not to be socounted for by the results of mere chemical investigntion; and it remainififor jodicions trial to determine the pecenliar propertices of the eeveral springs resorted to by the invalid.
These remarks especially apply to those hot springs which do not come under any of the preceding heads, as those of Buxton, Bristol, Matlock, Bath, etc., which, although not devoid of active mineral ingredients - calcareous salts especially predominating - seem to operate chiefly by their thermal condition, and as diluents. Bristol hot well has a temperature of $74^{\circ} \mathrm{Fahr}$, and contains about $5.7 \mathrm{gr}$. of sulphates, muriates, and carbonates of soda, lime, and magnesia, with some three cubic inches of carbonic acid gas, as well as minute portions of oxygen and nitrogen, in proportions different to those existing in the atmosphere. The Buxton and Matlock are not very dissimilar in temperature-the latter being $68^{\circ}$, the former $77^{\circ}$-or in saline constituents. These waters exert a marked diuretic action, diluting and promoting the urinary secretions, also stimulating the cutaneous function, and tending to confine the alvine evacuation. They are much used externally as baths, in gouty, rheumatic, and cutaneous disorders. Bath water, having, a temperature of $116^{\circ}$, and containing about 14 grs. of earthy salts, etc., is often successful in removing chlorosis and uterine disorders by its mild but prolonged action; its antacid and diuretic properties especially influencing those unhealthy constitutional conditions connected with atonic gout, chronic rheumaiism, its sequelæ and varieties, lumbago, sciatica, tic, paralysis; dyspepsia and its concomitants, pyrosis, hepatic disorders, urinary and squamous skin affections; in fact, wherever a debilitated and dopraved state of the system exists. These thermal waters are contra-indicated in cerebral, thoracic, or abdominal affections connected with rascular excitement. The continental therwal waters, Wiesbaden, Baden-Baden, Castein, and Pfeffers, are analogous to the English springs of this division in temperature and saline contents. The former waters, especially those of Wiesbaden, contain boracic acid, and isrourably influence most of the disorders just enumerated.

In concluding this outline of the remedial effects of mineral waters, it must be remarked, that nothing but a very general skefch could be attempted here on such an ex- 


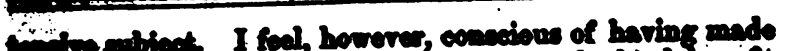

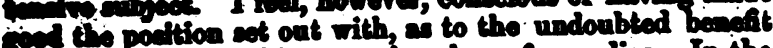
2. In the Wirce allution made to each spes howerex, minute sockwing an attempted; but it is hoped that, in giving the In ing constituents, the appropriate spring may be readily fred upon. Much must depend upon a just revier of the preivilities of erery particular case. Collateral subjects, as th their mode of administration, otc., will very materially Thet the result, and determine whether this class of medicinsl agents is to maintain the claims set up as to their infuence in removing functional disorder or incipient disinganiantion and decay.

28 Somercet Street, Portmen Square, Juno 1854

\section{ON GALLIC ACID;}

TTE BFIEDIAL POWEB IN THE BgYORREAGTO DIATHEBIS, AND IX DISEABES CHARACYERISED BY RETAIED FIBBD OB EXCESSIV E GECRETION.

By WILCHAM BAYES, M.D., Physician to the Brighton Dispensary.

[Read before the Medico-Chirurgical Society of Brighton and Sussex, Nov. 3rd, 1853.]

The few remarks which I bring under your considerition this evening relate to a therapeutic agent, whose value has hitherto, as I believe, been insufficiently appreciated by the profession at large.

In those works upon materia medica to which I have had access, gallic acid is chiefly lauded for its admirable power in arresting hæmorrhages; but even in these fluxes the mineral astringents are, as jet, held in more general estimation by the main body of the profession $\rightarrow$ preference which I do not think would be maintained were their relative merits better understood.

Iong prevailing practice indeed favours the exhibition of the mineral astringents in the treatment of hamorrhage, but afety and convenience in administration, as well as greater certainty in effect, will certainly be found in gallic acid. In it we have not only a powerful but a perfectly afe astringent, an advantage of no mean value over lead and other minerals, since, from the poisonous nature of these, their employment must be restricted : gallic acid, on the other hand, may be giren in continually repeated and increasing doses, only limited in their quantity and frequency by the removal of the necessity which called for their exhibition.

The truth of this proposition was well demonstrated in the case of hrmoptysis, reported by me in the Provincial Medical and Surgical Journal of Bept. 29th, 1852. In this case, I gave a drachm of the acid in less than two hours (in five-grain doses), and during the succeeding twentyfour hours another drachm was taken, with no distress or evil consequences of any lind, either then or scibsequently, to the general health. It is po mean advantage to possess an astringent which exercises its own proper power, and at the me time is neither excitant nor irritant, neither sedutive nor depressing.

Another advantage to be found in gallic acid is the ease and ropidity with which it enters the blood and saturates the syetem, whence it is not only to be preferred before miner ls but also before tannic scid.* In the case before illuded to, the bloody spute becarie perfectly inky in one hour and forty minutes. That the system was then completaly anturated with the remedy was proved by these pute being perfectly black throughout, not merely tinged or conted with black, as would have been the case had the contact with the remedy taken place only in the mouth and fuces. Simultaneously with this ints appenrance, the hromoptysis ceased. The effect produced upon the

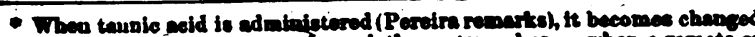

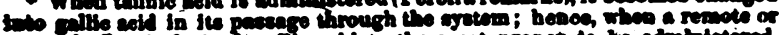

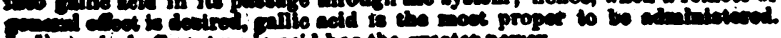

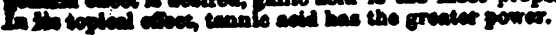

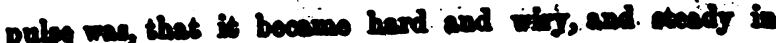
it beat.

The efoct of tannic and pallic soid on doad animal tissues are familiar to $u s$ in the procees of tanning. It tissues are familiar to us in and proceas of tanning. Itmonts hare sleo shown that a murated solution of gallic ments have also fhow drwn blood, both quickens cosgulaacid, mixed with freeh drawn blood, both quickens cosgulation and hardens the clot. gents thrown into the reins of animal argans of circulation; and since the astringent power of all vegetables depends and since the astringent pow allic acid contained in upon the amount of tannic and gallic acid contained in them, and since we have soen that gallic acid readily enters duced into the human system, gallic acid sets through its tendency to contract and condense the fibrous tissues, and to coagulate the vital fluids, wherever they hare this natural disposition.

Affecting, therefore, as it does both the circulating fiùid and its containing vessels, giving an increased proclivity and inds contraction in the one and towards coagulation in the perfect. wich the lifyedt dose may be administered, should render it our sheet-anchor in homorrhages, both. active and passive.

The ease and rapidity with which it enters the blood render it equally powerful to arrest hæmorrhage throughout the whole body. If the vital stream be oozing in out the whole body. If the atonic ressels, it will conpassive flux from relaxed and atonic ressels, if a boundtract them and steady the circulation; or if a bound ing puise forces an act ressel, it will contract this, and walls of some weakened vessel, it will contract this, and heart's action at the same time.

Where an overdose of gallic acid bas been taken, the pulse becomes small and wiry, the face grows pallid, a. pulse becomes is heard in the ears, the head feels dires, and faintess supervenes. These symptoms arise from tho and faintness superrenes. contraction of the capilaries and larger ressels produced by the astringency of intra-cranial circulation. But I conterforence with the be possible to poison a patient by the largest dose of the remedy when introduced by the mouth, because the capillary and distal vessels would become too contracted to receive any further supply, long ero a sufficient quantity could be carried into the blood to produca: dancerous effects upon the central circulation.

The ease with which gallic acid enters the circulation. renders it a most valuable remedy, not merely in hremorrhages, but also in those diseased habits of body in which rhages, but also in those diseased haminent and distressing symptom, and also in some other diatheses, which I will proceed to enumerate.

Dr. Scott Alison, in a paper on Tannic Acid, which appeared in the London Journal of Medicine for Jan. 1850, hac pecon its use as a tonic in dyspepsia-as a nervine recommended debility-as tending to improve the quality of the blood-as tending to arrest tubercle and malignants disease-and as valuable in rickets, in phthisis, in bronchitis, when accompanied by profuse expectoration, and is arresting colliquative diarrhoen and exhaustive sweats.

Dr. Burns, of Glasgow, praises the poweri of gallic acid in chlorosis, in doses of one hundred grains daily. From a consideration of its effects upon contractile tiosues and upon the various solid and liquid constituents of the aniupon the various mallic acid wherever relaxation of the one or too. great fuidity or dilution of the other were apparent, and exper fuidity or dilutifies its virtues in the rery classes of disease rience fully testifies its virues in the rery claseds of

In the following clasen of discase the remedy in worthy of erery confidence.

it. In actire hemorrhagees, from whatever organ or part of thit body the proceed.

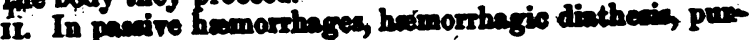
purn, ete. 